\title{
The relationship between clients' personality traits, working alliance and therapy outcome in a training context
}

\author{
Inga Dennhag ${ }^{A, B, C, D, E, F}$, Helene Ybrandt ${ }^{A, B, D, E, F}$, Anna Sundström ${ }^{A, C, D, E, F}$ \\ Department of Psychology, Umeå University, Umeå, Sweden
}

BACKGROUND

Clients' differences in personality include both psychopathology and normal personality variations and constitute an important factor for the therapeutic process and outcome. There is a lack of empirical data on the impact of clients' personalities on therapeutic relationships and outcomes, particularly in a training context.

\section{PARTICIPANTS AND PROCEDURE}

This longitudinal study investigated the relationships between client personality traits, changes in those traits after cognitive behavioral or psychodynamic short-term therapy, and clients' perceived working alliances with their therapists and their clinical outcomes at a university training clinic in Sweden. Participants were 138 clients with moderate psychological symptoms. Personality traits were measured using the Health-Relevant Personality Inventory.

\section{RESULTS}

The results showed that Antagonism, Impulsivity, Hedonic Capacity, and Negative Affectivity improved significantly during therapy, while Alexithymia did not. Pre-therapy personality traits were not related to perceived working alliances (Working Alliance Inventory) or therapeutic outcomes (Clinical Outcomes in Routine Evaluation Outcome Measure). Post-therapy personality traits negative affectivity, hedonic capacity and alexithymia were related to working alliance, and changes in personality traits were predictive of therapy outcome. The change in Hedonic $\mathrm{Ca}-$ pacity and Negative Affectivity explained about $20 \%$ of the variance in post-therapy symptoms after controlling for pre-therapy symptoms.

\section{CONCLUSIONS}

The results suggest that therapeutic foci on hedonism (extraversion) and negative affectivity (neuroticism) could be important for working alliance formation and symptom reduction in therapy. Future research should examine whether changes in clients' negative affectivity or hedonic capacity mediate the relation between perceived working alliance quality and clinical outcome in training and other psychotherapeutic contexts.

\section{KEY WORDS}

outcome; client personality traits; HP5i; psychotherapy training; alliance

CORResPonding AUthor - Inga Dennhag, Ph.D., Department of Psychology, Umeå University, 90187 Umeå, Sweden, e-mail: Inga.Dennhag@umu.se

Authors' Contribution - A: Study design · B: Data collection · C: Statistical analysis · D: Data interpretation .

E: Manuscript preparation · F: Literature search · G: Funds collection

to CITE this ARTICLE - Dennhag, I., Ybrandt, H., \& Sundström, A. (2017). The relationship between clients' personality traits, working alliance and therapy outcome in a training context. Current Issues in Personality Psychology, 5(2), $132-142$.

RECEIVED 07.10.2016 · REVIEWED 11.12.2016 · ACCEPTED 28.12.2016 · PUBLISHED 27.01.2017 


\section{BACKGROUND}

Abundant research demonstrates that clients and therapists build therapeutic relationships together, with the client assuming a central role as an active co-constructor who contributes to the relationship in unique ways depending on his or her personality traits and interpersonal skills. McWilliams (2012) concluded that the quality of a therapeutic relationship is based on the personalities of the client and the therapist and that the alliance, together with the client's and the therapist's personalities, contributes to the change in therapy. Coleman (2006) asserted that "client personality is deserving of further study as a potentially important influence on therapy process and outcome," perhaps serving as a moderator/mediator for the association between alliance and outcome. He pointed to the lack of empirical data on the impact of clients' personalities on therapeutic relationships and outcomes. The potential relevance of client personality to therapeutic processes and outcomes makes assessments of personality profiles potentially important to clinicians who tailor treatment approaches to their clients, because such profiles address both psychopathology (Zinbarg, Uliaszek, \& Adler, 2008) and normal personality variations (Coleman, 2006). This research has been based on experienced and professional therapists, and it is still unknown how trainees would form the relationship and treatment outcome compared to professional therapists. Minor differences between professionals and trainees have been found in studies (e.g. Okiishi et al., 2006; Hill \& Knox, 2013). More research is needed in this area.

One of the models that has been found useful in the study of client personality in relation to therapeutic process and outcome research is the five-factor model (FFM) of personality (e.g., Coleman, 2006; Hedman et al., 2014; Hirsh, Quilty, Bagby, \& McMain, 2012; John \& Srivastava, 1999; Krasner et al., 2009; Lee \& Bowen, 2015; Smits, Luyckx, Smits, Stinckens, \& Claes, 2015; Tang et al., 2009). The FFM represents the broadest, most consistent dimensions that have been used in investigations of personality traits (John \& Srivastava, 1999). The five personality traits are labeled Agreeableness, Openness, Extraversion, Neuroticism, and Conscientiousness.

Coleman (2006) investigated the relation between personality, based on the FFM, and working alliance, in a cross-sectional study of 103 heterogeneous psychiatric patients. He found moderate positive correlations between Agreeableness, Openness, Extraversion, and Conscientiousness and clients' working alliance ratings, but neuroticism was found to be unrelated. Similar results have been found in other studies. For example, Hirsh et al. (2012) reported a positive relationship between Agreeableness and alliance in a sample of 87 borderline patients. Smits et al. (2015) examined a sample of 557 psychiatric patients, and their results showed negative correlations between Emotional Dysregulation (a reciprocal of Neuroticism), Dissocial Behavior (an inverse of Agreeableness), and the contract (Task and Goal) components of the alliance.

Moreover, the personality traits of the FFM have shown high correlations with psychological problems and personality disorders (Campbell-Sills, Cohan, \& Stein, 2006; Giluk, 2009; Goodwin \& Friedman, 2006; Kendler, Gatz, Gardner, \& Pedersen, 2006; Kotov, Gamez, Schmidt, \& Watson, 2010; Saulsman \& Page, 2004; Quilty et al., 2008). A five-factor study (Trull \& Sher, 1994) showed that psychiatric disorders correlate with a profile of high scores on Neuroticism and Openness and lower scores on Agreeableness, Extraversion, and Conscientiousness. Neuroticism seems to be an especially strong predictor of health problems (e.g. Campbell-Sills et al., 2006; Giluk, 2009; Kendler et al., 2006; Quilty et al., 2008) and health service use (Lahey, 2009).

The personality traits of the FFM might change in the context of psychotherapy (De Fruyt, Van Leeuwen, Bagby, Rolland, \& Rouillon, 2006; Hedman et al., 2014; Krasner et al., 2009), but not always (Tang et al., 2009). De Fruyt et al. (2006) found in a longitudinal study of 599 depressed clients that the clients described themselves as slightly more emotionally stable, extraverted, open to experience, agreeable, and conscientious after pharmacotherapy and psychotherapy. Hedman et al. (2014) reported a significant reduction in Neuroticism in the therapy group compared to the control group in a randomized Internet study of 81 anxious clients. Krasner et al. (2009) measured 70 distressed physicians who received 12 months of mindfulness training. Conscientiousness and Emotional Stability showed small to moderately positive changes. Tang et al. (2009) published results from a randomized study of 120 depressed clients. Clients demonstrated changes in Neuroticism and Extraversion scores, but after controlling for baseline depression scores, the change in Neuroticism was no longer significant.

Although some studies have shown changes in personality traits following psychotherapy, they do not reveal whether or how such changes or pre-therapy personality traits predict symptom change. Few studies have investigated FFM personality traits as predictors of therapeutic change or clinical outcome. Lee and Bowen (2015) examined 39 men with drug abuse disorders who received mindfulness-based training. Their result indicated however that none of the FFM factors predicted outcomes regarding mindfulness when controlling for depression. Similarly, Blom et al. (2007) investigated 193 depressed patients. Severity and duration of depression was predictive of psychotherapy outcome, not pre-therapy personality factors. However, two studies investigated milder psychiatric conditions and personality traits, Spek, Nyklíček, Cuijpers and Pop (2008) found that lower neuroticism and higher depression scores at baseline predicted bet- 
ter outcome after group and internet-based treatment in 130 sub-threshold depressed patients. Krasner et al. (2009) reported that improvements in the personality traits of Conscientiousness and Emotional Stability correlated with changes in mindfulness.

A relatively new Swedish instrument based on the FFM, developed for use in research on personality and health, is the Health-relevant Personality Inventory (HP5i) (Gustavsson, Jönsson, Linder, \& Weinryb, 2003), which consists of five sub-scales: Antagonism, Impulsivity, Hedonic Capacity, Negative Affectivity, and Alexithymia. Each subscale was developed as a health-relevant aspect of a higher-order factor from the FFM and was theoretically or empirically associated with health and corresponded to one factor in the FFM. Impulsivity is a facet of Conscientiousness and has been found to predict risk-taking and unhealthy behavior and to be associated with personality pathology. Antagonism is a facet of Agreeableness and is theoretically related to health because a hostile outlook might cause interpersonal problems. Hedonic Capacity is an aspect of Extraversion that focuses on the capacity for experiencing pleasure and enjoyment. Negative Affectivity is a facet of Neuroticism and captures proneness to nervous tension and distress. Alexithymia is related to Openness and captures difficulties experiencing and expressing emotion, which corresponds to low scores on Openness (Gustavsson et al., 2003).

According to Gustavsson et al. (2003), the constructs measured by HP5i are likely to be relevant in explaining the effects of individual differences in vulnerability to illness and illness progression, as well as differences in psychosocial adaption to illness. Therefore, the HP5i might be a valuable instrument in psychotherapy research. To date, however, the HP5i has not been used in psychotherapy research, but findings from other health-relevant studies show promising results for the association between HP5i personality variables and health parameters (Axelsson, 2013; Gunnarsson, Gustavsson, Tengström, Franck, \& Fahlke, 2008).

The present study examined the relation between health-relevant personality traits, working alliance and psychotherapy outcomes in a training context. More specifically, it investigated whether the HP5i personality traits of Antagonism, Impulsivity, Hedonism, Negative Affectivity, and Alexithymia predict psychotherapy outcomes in a sample of outpatient clients in short-term psychotherapy with trainees as therapists, at a training clinic. This work sought to answer the following research questions: a) To what extent do personality traits change from preto post-therapy? b) How are pre-and post-therapy health-relevant personality traits related to working alliance at post treatment? c) Can pre-therapy personality traits or changes in personality traits during therapy predict therapy outcomes?

\section{PARTICIPANTS AND PROCEDURE}

The data used in this study are from the Outcome and Prediction of Outcome in Psychotherapy Training Programs project, a naturalistic outcome study of clients at an outpatient training clinic at Umeå University, Sweden. Data were collected between 2012 and 2015. The project was approved by the Swedish ethics board.

Clients were self-referred to the training clinic through an Internet website, and psychologists at the clinic performed the intake interviews and screenings. During their interviews, clients were asked to participate in the study and informed consent was obtained from those who chose to do so. Before the therapy was initiated, psychologists provided a computer-based questionnaire to the clients, including the instruments used in this study. The same questionnaire, in addition to a measure of working alliance, was administered to the clients by the therapist after the treatment had ended.

\section{PARTICIPANTS}

The study group consisted of 138 clients for whom both pre- and post-therapy data were available. The mean age was 28 years ( $S D=8.00$, range: $19-62$ years) and $72 \%$ were women. With respect to living situations, 35\% lived alone, $42 \%$ lived with a partner, and $23 \%$ had other arrangements. Employment status was as follows: $61 \%$ were students, $32 \%$ had full-time work, $1 \%$ was on sick leave, and $6 \%$ had other employment circumstances. Education levels were as follows: $76 \%$ had higher education, $20 \%$ had completed secondary school, and $4 \%$ reported other educational attainment. The clients' primary complaints were identity/self-image problems (78\%), relationship problems $(71 \%)$, anxiety $(69 \%)$, depression $(61 \%)$, crisis/stress (33\%), phobia (20\%), and other difficulties. Altogether, $90 \%$ reported more than two psychological problems. Values for personality factors (HP5i), psychological symptoms (The Clinical Outcomes in Routine Evaluation Outcome Measure [CORE-OM], Evans et al., 2000), and working alliance (Working Alliance Inventory [WAI], Horvath \& Greenberg, 1989), both pre- and post-therapy, are shown in Table 1. Exclusion criteria included severe eating disorders, severe depressive problems, suicidality, chronic problems, severe co-morbidity, and low functional level. The clients receiving psychotherapy had mild to moderate problems.

The study group of 138 clients and a group of 513 clients at the same clinic for whom only pre-therapy data were available were compared with respect to age, gender, main problems, HP5i factors, and pre-therapy symptoms in order to examine whether the study group was representative of the overall population 
Inga Dennhag, Helene Ybrandt, Anna Sundström

Table 1

Intraclass correlation coefficients of supervisors' impact on post measure scores for the two treatment conditions separately

\begin{tabular}{|c|c|c|c|c|c|c|}
\hline \multirow{2}{*}{ ICCs } & \multicolumn{2}{|c|}{ Coefficients $(r)$} & \multicolumn{2}{|c|}{$F$} & \multicolumn{2}{|c|}{ Significance } \\
\hline & PDT & CBT & PDT & CBT & PDT & CBT \\
\hline WAI (post-test) & -.08 & -.20 & 0.68 & 0.31 & n.s. & n.s. \\
\hline Core-OM Post-test & -.11 & .05 & 0.59 & 1.23 & n.s. & n.s. \\
\hline
\end{tabular}

Note. WAI - Working alliance inventory. Significance level was set to $\alpha=.05$.

of clinic clients. The analysis showed no statistically significant differences, which suggested that the study sample was representative of clinic clients in general.

In order to determine whether the study group could be considered a clinical one, comparisons were made with two normative groups. The first comparator was a Swedish normative group from CORE-OM (Elfström et al., 2012) consisting of 103 men and 126 women. The mean age was 27.50 years $(S D=8.00$, range: $17-56$ years) and all were students. The mean for the total score on the CORE-OM was $1.12(S D=0.77)$ for men and $1.17(S D=0.74)$ for women. One-sample $t$-tests showed that there were statistically significant differences between the normative group and the study group on pretests (men: $t(38)=5.31$, $p<.001$ and women: $t(98)=4.42, p<.001)$. The study group thus had significantly more psychological problems than the normative group.

The second group to which the study group was compared was a standard Swedish normative sample for the HP5i (Gunnarsson \& Gustavsson, 2013). That normative group consisted of 3,000 randomly selected subjects, aged 16 to 85 years, but only data for those aged 20 to 39 years were used in this analysis. The normative group's means and standard deviations for each scale were: Antagonism $(n=369, M=2.26$, $S D=0.70)$, Impulsivity $(n=369, M=2.14, S D=0.60)$, Hedonic Capacity $(n=369, M=3.19, S D=0.49)$, Negative Affectivity $(n=369, M=2.26, S D=0.61)$, and Alexithymia $(n=369, M=1.95, S D=0.62)$. One-sample $t$-tests showed statistically significant differences between the normative group and the study group on pretests (see Table 1 for means and standard deviations) on Hedonic Capacity $(t(137)=-5.11, p<.001)$, and Negative Affectivity $(t(137)=5.32, p<.001)$ but not on any of the other sub-scales. The study group scored significantly lower on Hedonic Capacity and higher on Negative Affectivity than the normative group.

\section{TRAINING CONDITIONS}

The training clinic offered two different psychotherapeutic modalities: cognitive behavioral therapy (CBT; Binder \& Betan, 2013) and psychodynamic therapy (PDT: Westbrook, Kennerly, \& Kirk, 2011). All therapies were short in duration, with a mean of
23 sessions (range: 7-33 sessions). Therapies lasted for one $(n=23)$ or two semesters $(n=113)$. Two clients terminated the therapy for different reasons, but the rest of the 136 therapies were fulfilled.

\section{TRAINEE THERAPISTS}

Therapies were conducted by 138 psychology students in the two last years of a five-year program, where each student treated one client. The mean age of the therapists was 27 years $(S D=4.11$, range: $22-47$ years), $70 \%$ were women, and all were native Swedes.

Psychotherapy training in Sweden is organized at a basic level and at an advanced level. At the basic level, basic knowledge is taught for a duration of 1.50 years on a part-time basis. The advanced level is the formal psychotherapist examination and takes place over three years part-time. In the current study, the psychology students were doing the basic level, as provided in the psychology program.

\section{SUPERVISORS}

The trainee therapists were supervised by 16 supervisors working at the clinic. They supervised between 1 and 21 students, on average treatments of 9 clients each. They were experienced licensed psychotherapists and had completed a three-year, part-time educational program in psychotherapy training. They supervised trainees in their own fields of expertise, either PDT or CBT. Of the 138 therapies, 61 were PDT and 77 were CBT. The total time of supervision was 52 hours for each group with three students.

\section{MEASURES}

The Health-Relevant Personality Inventory (HP5i; Gustavsson et al., 2003). The HP5i is a 20-item self-report personality instrument developed for use in health research. Each item is rated on a 4-point Likert scale ranging from 1 (does not apply at all) to 4 (applies completely). The items are distributed across five sub-scales: 1) Antagonism (hostile behavior; e.g., "If treated badly, I think one should strike back"), 2) Impulsivity (impulsive behavior; e.g., "I throw myself too hastily into things"), 
3) Hedonic Capacity (capacity to experience pleasure; e.g., "I enjoy life"), 4) Negative Affectivity (experience of negative feelings; e.g., "I often feel uncomfortable and ill at ease"), and 5) Alexithymia (inability to express emotions verbally; e.g., "I don't analyze my feelings"). These five sub-scales correspond to the five factors in the FFM (Hemphälä, Gustavsson, \& Tengström, 2013). Reliability estimates for the HP5i sub-scales have been found acceptable. Two studies (an adult twin study: Gustavsson et al., 2003, and a diabetes study: Gustavsson, Eriksson, Hilding, Gunnarsson, \& Ostensson, 2008) reported acceptable Cronbach's $\alpha$ for Antagonism (.65-.68), Impulsivity (.66-.78), Hedonic Capacity (.54-.69), Negative Affectivity (.67-.70), and Alexithymia (.61-.71). In the present study, the Cronbach's $\alpha$ for the pre-therapy HP5i ratings were .68 for Antagonism, .76 for Impulsivity, .63 for Hedonic Capacity, . 57 for Negative Affectivity, and .69 for Alexithymia.

The construct validity of the HP5i has been examined in previous studies. Confirmatory factor analyses have indicated acceptable model fit of the HP5i (Gustavsson et al., 2003; Gunnarsson et al., 2008). Support for convergent validity of the HP5i has been demonstrated in correlations with the corresponding sub-scales of the FFM instrument. All sub-scales were moderately correlated with the corresponding sub-scales of the FFM instrument $(r=-.42$ to $r=.64$ ), except for the Hedonic Capacity sub-scale, for which no significant correlation with Extraversion was found ( $r=-.05$ ) (Gustavsson et al., 2003). Moreover, correlations between HP5i scales and the Junior Temperament and Character Inventory and psychiatric symptoms provide support for convergent validity. For example, Negative Affectivity was positively related to measures of depression and anxiety, whereas Hedonic Capacity was negatively correlated with depression (Hemphälä et al., 2013).

The Working Alliance Inventory (WAI; Horvath \& Greenberg, 1989). The WAI was developed to measure clients' experiences of working alliances with their therapists. The questionnaire queries the components of the therapy as well as the parameters of goal, task, and bond. Each of the 34 items of the questionnaire is rated on a 7-point Likert scale ranging from 1 (never) to 7 (always), and higher scores reflect more positive ratings of the working alliance. The clients answered the WAI post-therapy; they were asked to rate how they perceived the alliance during the course of therapy. Reliability estimates of internal consistency are robust and high but vary between .77 and .92 in different studies with a mean of 87 (Hansson, Curry, $\&$ Bandalos, 2002), and test-retest reliability is acceptable (Goldberg, Rollins, \& McNary, 2004). The client version of WAI has shown convergent validity with the California Psychotherapy Alliance Scales $(r=.74$; Gaston, 1991) and the Penn Helping Alliance Scales ( $r=.85$; Alexander, Luborsky, Greenberg, \& Pinsof, 1986; Hatcher \& Barends, 1996). In the present study, internal consistency was .91 (Cronbach's $\alpha$ ) for the total scale at the end of the therapy.

The Clinical Outcomes in Routine Evaluation Outcome Measure (CORE-OM; Evans et al., 2000). The CORE-OM is a 34-item self-report instrument for ascertainment of psychological problems. It measures subjective wellbeing (4 items), problems/symptoms (12 items), life/social functioning (12 items), and risk to self and others (6 items). Each item is rated on a 5-point Likert scale ranging from 0 (never) to 4 (almost all the time). In this study, the mean scores of the total scale were used (Evans et al., 2002). The Swedish version has shown excellent acceptability with high internal consistency (.93-.94) and test-retest reliability (Spearman's $\rho=.85$ ) as well as acceptable convergent validity (Elfström et al., 2012) of the total scale. In the present study, internal consistency was .91 (Cronbach's $\alpha$ ) for the total scale at pretest.

\section{STATISTICAL ANALYSIS}

All analyses were conducted using IBM Statistics for Windows, Version 22.0. As the outcome data are nested within supervisors and treatment modalities (CBT/ PDT), we calculated intraclass correlations (ICCs) in search of a correlation of outcome among clients treated by therapists having the same supervisor, for the two treatment modalities separately. These coefficients would render significant results if data from clients correlated more strongly with other clients treated by therapists having the same supervisor than they would with all other clients. The ICCs were computed from an ANOVA source table in accordance with procedures suggested by Baldwin et al. (2011) and Kenny, Manetti, Pierro, Livi, and Kashy (2002). The ICC estimates the proportion of variance in the outcome variables that is attributable to supervisors.

Because the two dependent variables working alliance and post-treatment symptoms were only moderately inter-correlated $(r=-.35, p<.001)$, their relationship with personality traits was examined in separate analyses. The relationship between personality traits and working alliance was examined with Pearson correlations, due to the cross-sectional data (i.e. the fact that working alliance was measured only at the end of the therapy). To examine the relations between personality traits and post-therapy symptoms, two hierarchical regression analyses were performed. A positive personality change score implies that the scale score decreased after therapy, whereas a negative change score implies that the scale score increased after therapy.

\section{MODEL FIT AND TEST OF ASSUMPTIONS}

Residual and scatter plots indicated that the assumptions of normality, linearity, and homoscedasticity 
were all satisfied (Tabachnick \& Fidell, 2013; Field, 2009). No multicollinearity was found (Tabachnick \& Fidell, 2013). In the regression model where the dependent variable was post-therapy symptoms, and pre-therapy symptoms, treatment length and modality and change in personality were each entered as independent variables, the inspection of influential cases revealed that in 9 and 8 cases, respectively, the values of Leverage and Mahalanobis distances were higher than the critical values, indicating that those cases exerted undue influence on the regression parameters. Those cases were removed and the regression analyses were conducted on the reduced sample of 129 subjects.

\section{RESULTS}

\section{INTRACLASS CORRELATION COEFFICIENTS OF WITHIN SUPERVISOR CORRELATIONS BETWEEN CLIENTS}

Intraclass correlations resulted in four intraclass-correlation coefficients for the two respective treatment modalities on the two outcome measures: working alliance (WAI) and post-treatment symptoms (CORE-OM). No significant intraclass correlations were found, indicating that there were no supervisor effects (see Table 1).

\section{TREATMENT MODALITIES, LENGTH OF TREATMENT}

There were no differences in working alliance ratings $(t(136)=1.57, p=.160 /$ n.s. $)$ or post-treatment symptoms $(t(136)=-0.82, p=.556)$ between clients in the two different treatment modalities. Due to this, the clients in the two treatment groups were collapsed into one group in the following analyses.

\section{EFFECT OF THERAPY ON PERSONALITY AND SYMPTOMS}

As shown in Table 2, there were statistically significant differences between pre-therapy and post-therapy scores for the personality variables of Antagonism, Impulsivity, Hedonic Capacity, and Negative Affectivity, but not for Alexithymia. The largest effect size was observed for Negative Affectivity. The results showed that Antagonism, Impulsivity, and Negative Affectivity decreased, whereas Hedonic Capacity increased. In addition, symptom levels (CORE-OM) improved significantly from before to after therapy, with a large effect size.

\section{THE RELATION BETWEEN PRE- AND POST-THERAPY PERSONALITY TRAITS AND WORKING ALLIANCE}

The results showed no significant relationships between personality traits before therapy and the ratings of working alliance at the end of therapy (see Table 3). However, for the post-therapy personality ratings, negative affectivity and alexithymia were negatively associated with working alliance, whereas hedonic capacity was positively associated with working alliance.

Table 2

Descriptive statistics and paired t-test results for the personality variables, psychiatric symptoms and workingalliance ratings

\begin{tabular}{|c|c|c|c|c|c|c|c|c|}
\hline & \multicolumn{2}{|c|}{ Pre-test } & \multicolumn{2}{|c|}{ Post-test } & \multirow{2}{*}{$\begin{array}{c}95 \% \mathrm{Cl} \text { for mean } \\
\text { difference }\end{array}$} & \multirow[t]{2}{*}{$t$} & \multirow[t]{2}{*}{$d f$} & \multirow[t]{2}{*}{$d$} \\
\hline & $M$ & $S D$ & $M$ & $S D$ & & & & \\
\hline \multicolumn{9}{|c|}{ Personality trait } \\
\hline Antagonism & 1.86 & 0.61 & 1.76 & 0.59 & $0.01-0.19$ & $2.24^{*}$ & 137 & .18 \\
\hline Impulsivity & 2.21 & 0.65 & 2.09 & 0.67 & $0.03-0.21$ & $2.73^{* *}$ & 137 & .23 \\
\hline $\begin{array}{l}\text { Hedonic } \\
\text { Capacity }\end{array}$ & 2.99 & 0.47 & 3.18 & 0.46 & $-0.27--0.11$ & $-4.66^{* * *}$ & 137 & .40 \\
\hline $\begin{array}{l}\text { Negative } \\
\text { Affectivity }\end{array}$ & 2.53 & 0.60 & 2.24 & 0.58 & $0.21-0.38$ & $6.43^{* * *}$ & 137 & .54 \\
\hline Alexithymia & 1.61 & 0.54 & 1.59 & 0.49 & $-0.06-0.10$ & 0.53 & 137 & - \\
\hline $\begin{array}{l}\text { Psychiatric } \\
\text { symptoms }\end{array}$ & 1.44 & 0.51 & 0.97 & 0.47 & $0.38-0.56$ & $10.35^{* * *}$ & 137 & .89 \\
\hline $\begin{array}{l}\text { Working } \\
\text { alliance }\end{array}$ & - & - & 6.33 & 0.47 & & & & \\
\hline
\end{tabular}


Table 3

Pearson correlations between working alliance and personality traits pre-and post-therapy

\begin{tabular}{|c|c|c|c|c|c|c|c|c|c|c|}
\hline \multicolumn{11}{|c|}{ Personality traits } \\
\hline & \multicolumn{2}{|c|}{ Antagonism } & \multicolumn{2}{|c|}{ Impulsivity } & \multicolumn{2}{|c|}{$\begin{array}{l}\text { Hedonic } \\
\text { Capacity }\end{array}$} & \multicolumn{2}{|c|}{$\begin{array}{c}\text { Negative } \\
\text { Affectivity }\end{array}$} & \multicolumn{2}{|c|}{ Alexithymia } \\
\hline & Pre & Post & Pre & Post & Pre & Post & Pre & Post & Pre & Post \\
\hline $\begin{array}{l}\text { Working- } \\
\text { alliance }\end{array}$ & -.10 & -.01 & -.12 & -.16 & -.01 & $.20^{*}$ & -.05 & $-.22^{* *}$ & -.16 & $-.29^{* *}$ \\
\hline
\end{tabular}

\section{PRE-THERAPY PERSONALITY TRAITS AS PREDICTORS OF POST-THERAPY SYMPTOMS}

To investigate whether the personality variables (Antagonism, Impulsivity, Hedonic Capacity, Negative Affectivity, and Alexithymia) measured before therapy predict post-therapy symptoms, when controlling for pre-treatment symptoms, treatment modality and treatment length, a hierarchical multiple regression analysis was performed. The analysis revealed that at stage 1 , pre-therapy symptoms contributed significantly to the regression model $(F(1,136)=28.35$, $p<.001)$ and accounted for $16.60 \%$ of the variance in post-therapy symptoms. Introducing treatment modality and treatment length at stage 2 , and personality variables at stage 3 , did not explain additional variance and thus did not improve the model.

\section{CHANGE IN PERSONALITY TRAITS AS PREDICTORS OF POST-THERAPY SYMPTOMS}

Next, we examined whether the change in personality variables during therapy predicted post-therapy symptoms. A hierarchical multiple regression analysis was performed with post-therapy symptoms as the dependent variable. The results showed that at stage 1 , pre-therapy symptoms contributed significantly to the regression model $(F(1,127)=22.16$, $p<.001)$ and accounted for $14.20 \%$ of the variance in post-therapy symptoms (see Table 4 ). Introducing treatment modality and treatment length in step 2 did not improve the model significantly. However, introducing change in personality variables in step 3 explained an additional $21.10 \%$ of variation in post-therapy symptoms, and this change in $R^{2}$ was significant $(F(8,120)=9.74, p<.001)$. When controlling for pre-therapy symptoms, Hedonic Capacity was positively correlated and Negative Affectivity was negatively correlated with post-therapy symptoms, which implies that increases in Hedonic Capacity and reductions in Negative Affectivity during therapy correlate with lower post-therapy symptom scores.

\section{DISCUSSION}

The present study investigated the relations between health-relevant traits of personality, working alliance and therapy outcomes in a sample of clients at a training clinic. Overall, we found that personality traits change during therapy and that these changes are predictive of therapy outcome in terms of psychological problems. We also found that personality traits as assessed post-therapy are related to perceived working alliance.

\section{CHANGES IN PERSONALITY TRAITS}

This study demonstrated changes in the personality traits of Antagonism, Impulsivity, Hedonic Capacity,

Table 4

Results of hierarchical multiple regression analysis predicting post-treatment symptoms from change in personality variables. Only significant results are presented

\begin{tabular}{|c|c|c|c|c|c|}
\hline & $B$ & SE $B$ & $\beta$ & $t$ & Adj. $R^{2}$ \\
\hline \multicolumn{6}{|l|}{ Stage 1} \\
\hline Pre-treatment symptoms & .35 & .08 & .39 & $4.71^{* * *}$ & .14 \\
\hline \multicolumn{6}{|l|}{ Stage 2} \\
\hline Pre-treatment symptoms & .49 & .07 & .53 & $7.14^{* * *}$ & .35 \\
\hline$\Delta$ Hedonic Capacity & .46 & .08 & .44 & $5.68^{* * *}$ & \\
\hline$\Delta$ Negative affectivity & -.14 & .07 & -.15 & $-2.04^{*}$ & \\
\hline
\end{tabular}


and Negative affectivity during therapy. The largest change, which was moderate in terms of effect size, was observed for Negative Affectivity, which decreased with therapy. The second greatest changes were observed for Hedonic Capacity, followed by Impulsivity and Antagonism; however, these changes were all small in magnitude (Cohen, 1988). The change in Negative Affectivity is in accord with earlier findings (De Fruyt et al., 2006; Hedman, et al., 2014; Krasner et al., 2009) showing moderate changes in neuroticism during therapy. Moreover, the change in Hedonic Capacity was also consistent with previous studies demonstrating small but statistically significant changes in Extraversion during therapy (De Fruyt et al., 2006; Krasner et al., 2009; Tang et al., 2009). However, Hedman et al. (2014) did not find a significant change following an Internet-based cognitive therapy. The effect sizes for changes in Neuroticism and Hedonic Capacity observed in the present study were greater than in previous studies (Hedman et al., 2014; Krasner et al., 2009). One explanation for this could be that the HP5i instrument differs from traditional FFM measurements and taps more health-relevant aspects of the FFM (Hemphälä et al., 2013) that might be more closely related to psychological symptoms. Alexithymia did not change in this study, likely reflecting a floor effect in the present sample prior to therapy.

Because the primary changes demonstrated in the present study were on the neuroticism-related sub-scale, one could argue that such traits are more related to state psychopathology (Kotov et al., 2010; Lahey, 2009) and therefore more amenable to change in therapy than the other personality traits. Neuroticism (along with extraversion) is a strong predictor of psychiatric morbidity and health service use (Lahey, 2009). Therefore, it is encouraging that the results from the present study show a decline in neuroticism ratings after psychotherapy.

\section{THE RELATIONSHIP BETWEEN PERSONALITY TRAITS AND WORKING ALLIANCE}

The results indicated that post-therapy ratings of Alexithymia and Negative Affectivity were negatively related and Hedonic Capacity was positively related to working alliance. Similar results have been found in other studies. More alexithymia (low scores on Openness) and less hedonic capacity (low scores on Extraversion) have been related to lower social competence, insecure relations and worse working alliance (Coleman, 2006; Mohaupt, Holgersen, Binder, \& Höstmark Nielsen, 2006), and more negative affect or neuroticism has been shown to correlate negatively with the working alliance (Smits et al., 2015).

A possible explanation for the lack of a correlation between pre-test ratings and working alliance could be intake factors. Clients with more severe personality problems could be expected to have more problematic personality traits (Hirsh et al., 2012) than ours. In our sample, clients had mild to moderate psychological problems and only differed from a normative sample with respect to the personality traits of Hedonic Capacity and Negative Affectivity. Therefore, we would not have expected significant predictive effects of the other traits.

\section{PERSONALITY TRAITS AS PREDICTORS OF THERAPY OUTCOME}

Based on previous studies, one could expect that personality traits would affect therapeutic outcome (Coleman, 2006; Hirsh et al., 2012; Krasner et al., 2009; Smits et al., 2015; Spek et al., 2008). Surprisingly, pre-therapy personality traits did not predict post-therapy symptoms in the present study; only pre-therapy symptoms did. This result was, however, consistent with other studies (Blom et al., 2007; Lee \& Bowen, 2015), which found that none of the pre-therapy personality traits predicted outcome when controlling for depression. Spek et al. (2008), who obtained different results, were investigating group and internet-based treatment in depressed patients.

Finally, this study investigated whether changes in personality traits during therapy predict therapy outcome. Previous work (e.g., Coleman et al., 2006) supports the potential of therapy to change personality measures. Our results revealed that increases of $\mathrm{He}-$ donic Capacity and reductions in Negative Affectivity were related to reductions in post-therapy symptoms after controlling for pre-therapy symptoms. Surprisingly, Hedonic Capacity and Negative Affectivity explained $21.10 \%$ of the variance in post-therapy symptoms. This result is consistent with the report of Krasner et al. (2009), who found that changes in emotional stability (Neuroticism) correlated with improvements in mindfulness in a sample of well-functioning but distressed physicians.

One possible explanation for the finding that $\mathrm{He}$ donic Capacity and Negative Affectivity changed during therapy, and predicted post-therapy symptom scores, relates to the content of the therapy. It is possible that some of the contributors to Hedonic Capacity and Negative Affectivity ratings were themes in therapy. If the substance of these items were addressed in therapy, it might have improved subjects' perceptions of their alliances and outcomes.

Previous studies of personality trait changes predicting therapy outcome are scant. Against this background, we find the results of the current study to be encouraging because they suggest that reducing neuroticism might result in improvements in therapy outcome. Future work should investigate whether changes in clients' Negative Affectivity or Hedonic 
Capacity mediate working alliance or outcome in other contexts.

\section{STRENGTHS}

To our knowledge, the present study is the first investigation to report changes in personality traits in a heterogeneous sample with a wide range of problems, which might be more representative of actual clinic populations. In addition, most previous studies employed cross-sectional experimental designs (Coleman, 2006; Kotov et al., 2010; Smits et al., 2015), whereas the present investigation was longitudinal. Another strength of the present study is the use of two different outcome measures: working alliance and post-therapy symptoms, tapping two different but likely related domains of interest.

\section{LIMITATIONS}

There are notable limitations of the present study. First, the study group consisted of a large, heterogeneous sample of well-functioning clients, most of whom suffered from moderate anxiety, depression, and/or relationship problems. Statistically, this group can be expected to change less than a group composed of clients with more severe conditions. It is also likely that a more heterogeneous sample with wider ranges of personality factor Alexithymia and ratings of working alliance would demonstrate stronger correlations between personality variables and the outcome measures. Moreover, the results were averaged for all clients and may not show differences which could be due to subgroups such as groups with different clinical diagnoses. It would be interesting to investigate subgroups in further research.

Second, the study sample was recruited from an outpatient university clinic and its generalizability to lower-functioning populations with more severe symptoms, and with professional therapists, remains to be investigated. Moreover, the measure of working alliance was only administered post-therapy. In order to examine how personality traits and changes in personality traits covary with working alliance, repeated measures of working alliance during the course of therapy would be needed.

Thirdly, this study did not control for therapist effects. Usually, around 5\% variance in psychotherapy are due to therapist effects (Baldwin \& Imel, 2013), and greater therapist effects are expected when the therapists are inexperienced (Crits-Christoph et al., 1991). In the current study, trainees were therapists, and that may have caused a small decrease in outcome. However, some of the therapist effects may have been overcome by supervision, because studies have shown no or small differences between trainees and professional therapists (e.g. Okiishi et al., 2006; Hill \& Knox, 2013).

Finally, a potential shortcoming of the study is its use of a relatively new instrument in this sort of research. One might also question whether health-relevant personality traits are meaningful variables in these types of studies, or if they are merely indicators of state-like symptoms. The HP5i correlated moderately with psychological symptoms before therapy (Hedonic Capacity: $r=-.50$; Negative Affectivity: $r=.39$ on CORE-OM), but the variance inflation factor did not indicate a multicollinearity problem. Therefore, we argue that health-relevant personality scales capture different constructs than the pre- and post-therapy symptom measure does (Gustavsson et al., 2003; Hemphälä et al., 2013). Although the results from validity studies generally provide support for the validity of the HP5i, support for convergent validity for the sub-scale of Hedonic Capacity is lacking. Conducting more validity and reliability studies on the HP5i, as well as replicating our study with other samples, might provide further evidence of the soundness of the HP5i as well as whether the HP5i measures traits or states.

\section{CONCLUSIONS}

The present study indicates that the client's personality traits change moderately in training therapy, especially hedonic capacity and negative affectivity. The client's personality traits before therapy might not affect post-therapy working alliance or outcome if the clients have moderate psychological problems. An interesting investigation would be to investigate how personality traits, specifically Hedonic Capacity, Negative Affectivity and Alexithymia, affect the alliance during the psychotherapy process. It appears that Hedonic Capacity and Negative Affectivity are especially important to monitor and work with during therapy because favorable changes in these traits might affect clients' perceptions of post-therapy levels of psychiatric symptoms.

\section{ENDNOTE}

Additional information regarding the equations and models can be obtained directly from the first author.

\section{RefERENCES}

Alexander, L. B., Luborsky, L., Greenberg, L. S., \& Pinsof, W. M. (1986). The Penn Helping Alliance scales. In L. S. Greenberg \& W. M. Pinsof (eds.), The Psychotherapeutic Process: A Research Handbook (pp. 325-366). New York: The Guilford Press. 
Axelsson, M. (2013). Personality and reasons for not using asthma medication in young adults. Heart \& Lung, 42, 241-246. doi: 10.1016/j.hrtlng.2013.01.005

Baldwin, S. A., Murray, D. M., Shadish, W. R., Pals, S. L., Holland, J. M., Abramowitz, J. S., ..., et al. (2011). Intraclass correlation associated with therapists: estimates and applications in planning psychotherapy research. Cognitive Behaviour Therapy, 40, 15-33. doi: 10.1080/16506073.2010.520731

Baldwin, S. A., \& Imel, Z. E. (2013). Therapist effects, findings and methods. In M. J. Lambert (ed.), Bergin and Garfield's handbook of psychotherapy and behavior change ( $6^{\text {th }}$ ed.) (pp. 258-297). New York, NY: Wiley.

Binder, J. L., \& Betan, E. J. (2013). Core competencies in brief dynamic psychotherapy: becoming a highly effective and competent brief dynamic psychotherapist. New York: Routledge.

Blom, M. B. J., Spinhoven, P., Hoffman, T., Jonker, K., Hoencamp, E., Haffmans, P. M. J., \& van Dyck, R. (2007). Severity and duration of depression, not personality factors, predict short term outcome in the treatment of major depression. Journal of Affective Disorders, 104, 119-126. doi: 10.1016/j. jad.2007.03.010

Campbell-Sills, L., Cohan, S. L., \& Stein, M. B. (2006). Relationship of resilience to personality, coping, and psychiatric symptoms in young adults. $\mathrm{Be}$ haviour Research and Therapy, 44, 585-599. doi: 10.1016/j.brat.2005.05.001

Crits-Christoph, P., Baranackie, K., Kurcias, J. S., Beck, A. T., Carroll, K., Perry, K., ..., et al. (1991). Meta-analysis of therapist effects in psychotherapy outcome studies. Psychotherapy Research, 1, 81-91. doi: 10.1080/10503300500265025

Cohen, J. (1988). Statistical power analysis for the behavioral sciences $\left(2^{\text {nd }}\right.$ ed.). Hillsdale, NJ: Lawrence Earlbaum Associates.

Coleman, D. (2006). Client personality, working alliance and outcome: A pilot study. Social Work in Mental Health, 4, 83-98. doi: 10.1300/ J200v04n04_06

De Fruyt, F., Van Leeuwen, K., Bagby, R. M., Rolland, J.-P., \& Rouillon, F. (2006). Assessing and interpreting personality change and continuity in patients treated for major depression. Psychological Assessment, 18, 71-80. doi: 10.1037/1040-3590.18.1.71

Elfström, M. L., Evans, C., Lundgren, J., Johansson, B., Hakeberg, M., \& Carlsson, S. G. (2012).Validation of the Swedish version of the Clinical Outcomes in Routine Evaluation Outcome Measure (COREOM). Clinical Psychology and Psychotherapy, 20, 447-455. doi: 10.1002/cpp. 1788

Evans, C., Connell, J., Barkham, M., Margison, F., McGrath, G., Mellor-Clark, J., \& Audin, K. (2002). Towards a standardized brief outcome measure: psychometric properties and utility of the CORE-
OM. British Journal of Psychiatry, 180, 51-60. doi: 10.1192/bjp.180.1.51

Evans, C., Mellor-Clark, J., Margison, F., Barkham, M., Audin, K., Connell, J., \& Mcgrath, G. (2000). CORE: Clinical outcomes in routine evaluation. Journal of Mental Health, 9, 247-255.

Field, A. (2009). Discovering statistics using SPSS (3 $3^{\text {rd }}$ ed). Washington DC: SAGE.

Gaston, L. (1991). Reliability and criterion-related validity of the California psychotherapy alliance scales-patient version. Psychological Assessment, 3, 68-74. doi: 10.1037/1040-3590.3.1.68

Giluk, T. L. (2009). Mindfulness, Big five personality and affect: A meta-analysis. Personality and Individual Differences, 47, 805-811. doi: 10.1016/j. paid.2009.06.026

Goodwin, R. D., \& Friedman, H. S. (2006). Health status and the five-factor personality traits in a national representative sample. Journal of Health Psychology, 11, 643-654. doi: 10.1177/1359105306066610

Goldberg, R. W., Rollins, A. L., \& McNary, S. W. (2004). The Working Alliance Inventory: Modification and use with people with mental illness in a vocational rehabilitation program. Psychiatric Rehabilitation Journal, 27, 267-270. doi: 10.2975/27.2004.267.270

Gunnarsson, M., \& Gustavsson, J. P. (2013). Normative data for HP5i based on SOM investigation 2011. Unpublished Manuscript.

Gunnarsson, M., Gustavsson, J. P., Tengström, A., Franck, A., \& Fahlke, C. (2008). Personality traits and their associations with substance use among adolescents. Personality and Individual Differences, 45, 356-360. doi: 10.1016/j.paid.2008.05.004

Gustavsson, J. P., Eriksson, A. K., Hilding, A., Gunnarsson, M., \& Ostensson, C. G. (2008). Measurement invariance of personality traits from a Fivefactor model perspective: Multi-group confirmatory factor analyses of the HP5 inventory. Scandinavian Journal of Psychology, 49, 459-467. doi: 10.1111/j.1467-9450.2008.00654.x

Gustavsson, J. P., Jönsson, E. G., Linder, J., \& Weinryb, R. M. (2003). The HP5 inventory: definition and assessment of five health-relevant personality traits from a five-factor model perspective. Personality and Individual Differences, 35, 69-89. doi: 10.1016/S0191-8869(02)00142-3

Hansson, W. E., Curry, K. T., \& Bandalos, D. L. (2002). Reliability generalization of working alliance inventory scale scores. Educational and Psychological Measurement, 62, 659-673. doi: 10.1177/0013164402062004008

Hatcher, R. L., \& Barends, A. W. (1996). Patients' view of the alliance in psychotherapy: exploratory factor analysis of three alliance measures. Journal of Consulting and Clinical Psychology, 64, 1326-1336. doi: 10.1037/0022-006x.64.6.1326

Hedman, E., Andersson, G., Lindefors, N., Gustavsson, P., Lekander, M., Rűck, C., ..., et al. (2014). Person- 
ality change following internet based cognitive behavior therapy for severe health anxiety. PLoS One, 9, 1-18. doi: 10.1371/journal.pone.0113871

Hemphälä, M., Gustavsson, P. J., \& Tengström, A. (2013). The validity of the Health-relevant Personality Inventory (HP5i) and the Junior Temperament and Character Inventory (JTCl) among adolescents referred for a substance misuse problem. Journal of Personality Assessment, 95, 398-406. doi: 10.1080/00223891.2012.735301

Hill, C. E., \& Knox, S. (2013). Training and supervision in psychotherapy. In M. J. Lambert (ed.), Bergin and Garfield's handbook of psychotherapy and behavior change (6 $6^{\text {th }}$ ed.) (pp. 775-812). New York, NY: Wiley.

Hirsh, J. B., Quilty, L. C., Bagby, R. M., \& McMain, S. F. (2012). The relationship between agreeableness and the development of the working alliance in patient with borderline personality disorder. Journal of Personality Disorders, 26, 616-627. doi: 10.1521/pedi.2012.26.4.616

Horvath, A. O., \& Greenberg, L. S. (1989). Development and validation of the Working Alliance Inventory. Journal of Counseling Psychology, 36, 223-233. doi: 10.1037/0022-0167.36.2.223

John, O. P., \& Srivastava, S. (1999). The Big Five Trait taxonomy: History, measurement, and theoretical perspectives. In L. A. Pervin \& O. P. John (eds.), Handbook of personality: Theory and Research $\left(2^{\text {nd }}\right.$ ed.) (pp. 102-138). New York. NY: Guilford Press.

Kendler, K. S., Gatz, M., Gardner, C. O., \& Petersen, N. L. (2006). Personality and major depression: A Swedish longitudinal, population-based twin study. Archives of General Psychiatry, 63, 11131120. doi: 10.1001/archpsyc.63.10.1113

Kenny, D. A., Manetti, L., Pierro, A., Livi, S., \& Kashy, D. A. (2002). The statistical analysis of data from small groups. Journal of Personality and Social Psychology, 83, 126-137. doi: 10.1037//0022-3514.83.1.126

Kotov, R., Gamez, W., Schmidt, F., \& Watson, D. (2010). Linking "big” personality traits to anxiety, depressive, and substance use disorders: A meta-analysis. Psychological Bulletin, 136, 768-821. doi: 10.1037/a0020327

Krasner, M. S., Epstein, R. M., Beckman, H., Suchman, A. L., Chapman, B., Mooney, C. J., \& Quill, T. E. (2009). Association of educational program in mindful communication with burnout, empathy, and attitudes among primary care physicians. JAMA, 302, 1284-1293. doi: 10.1001/jama.2009.1384

Lahey, B. B. (2009). Public health significance of neuroticism. American Psychology, 64, 241-256. doi: 10.1037/a0015309

Lee, K.-H., \& Bowen, S. (2015). Relation between personality traits and mindfulness following mindfulness-based training: A study of incarcerated individuals with drug abuse disorders in Taiwan. International Journal of Mental Health and Addiction, 13, 413-421. doi: 10.1007/s11469-014-9533-y
McWilliams, N. (2012). Beyond traits: Personality as intersubjective themes. Journal of Personality Assessment, 94, 563-570. doi: 10.1080/00223891.2012.711790

Mohaupt, H., Holgersen, H., Binder, P.-E., \& Höstmark Nielsen, G. (2006). Affect consciousness or mentalization? A comparison of two concepts with regard to affect development and affect regulation. Scandinavian Journal of Psychology, 47, 237-244. doi: 10.1111/j.1467-9450.2006.00513.x

Okiishi, J. C., Lambert, M. J., Eggett, D., Nielson, L., Dayton, D. D., \& Vermeersch, D. A. (2006). An analysis of therapist treatment effects: Toward providing feedback to individual therapists on their clients' psychotherapy outcome. Journal of Clinical Psychology, 62, 1157-1172. doi: 10.1002/ jclp.20272

Quilty, L. C., De Fruyt, F., Rolland, J.-P., Kennedy, S. H., Rouillon, P. F., \& Bagby, R. M. (2008). Dimensional personality traits and treatment outcome in patients with major depressive disorder. Journal of Affective Disorders, 108, 241-250. doi: 10.1016/j. jad.2007.10.022

Saulsman, L. M., \& Page, A. C. (2004). The five-factor model and personality disorder empirical literature: A meta-analytic review. Clinical Psychology Review, 23, 1055-1085.

Smits, D., Luyckx, K., Smits, D., Stinckens, N., \& Claes, L. (2015). Structural characteristics and external correlates of the Working Alliance Inventory-Short Form. Psychological Assessment, 27, 545-551. doi: 1040-3590/15/\$12.00.

Spek, V., Nyklíček, I., Cuijpers, P, \& Pop, V. (2008). Predictors of outcome of group and Internet-based cognitive behavior therapy. Journal of Affective Disorders, 105, 137-145. doi: 10.1016/j. jad.2007.05.001

Tabachnick, B. G., \& Fidell, L. S. (2013). Using multivariate statistics, 6/E. Instock: Pearson.

Tang, T. Z., DeRubeis, R. J., Hollon, S., Amsterdam, J., Shelton, R., \& Schalet, B. (2009). Personality change during depression treatment. Archives of General Psychiatry, 66, 1322-1330. doi: 10.1001/ archgenpsychiatry.2009.166

Trull, T. J., \& Sher, K. J. (1994). Relationship between the Five-factor model of personality and Axis I disorders in a nonclinical sample. Journal of Abnormal Psychology, 103, 350-360. doi: 10.1037/0021843X.103.2.350

Westbrook, D., Kennerly, H., \& Kirk, J. (2011). An introduction to cognitive behavior therapy: skills and applications ( $2^{\text {nd }}$ ed.). London: SAGE.

Zinbarg, R. E., Uliaszek, A. A., \& Adler, J. M. (2008). The role of personality in psychotherapy for anxiety and depression. Journal of Personality, 76, 1649-1688. doi: 10.1111/j.1467-6494.2008.00534.x 